\title{
Distal ureteral stricture: An unexpected complication of further adjuvant intravesical mitomycin C thermotherapy
}

\author{
Mehmet Umul, MD; ${ }^{*}$ Muammer Altok, MD; ${ }^{*}$ Mustafa Güneş, MD; ${ }^{*}$ Ali F. Şahin, MD; ${ }^{\dagger}$ R. Taner Divrik, MD ${ }^{\dagger}$
}

*Süleyman Demirel University, Faculty of Medicine, Department of Urology, Isparta, Turkey; ${ }^{\dagger}$ Şifa University, Faculty of Medicine, Department of Urology, Izmir, Turkey

Cite as: Can Urol Assoc J 2014;8(5-6):e453-4. http://dx.doi.org/10.5489/cuaj.1991 Published online June 19, 2014.

\section{Abstract}

We present a case of distal ureteral obstruction in relation to further adjuvant intravesical thermochemotherapy with mitomycin $\mathrm{C}$ (MMC) for non-muscle invasive bladder cancer (NMIBC). We also discuss the diagnostic procedures and management of this recurrent case.

\section{Introduction}

Transuretral resection of the bladder tumour (TURBT) is still recognized as the primary treatment option for non-muscle invasive bladder tumours (NMIBT). However, recurrence and progression are still issues despite the radical resection. The European Association of Urology (EAU) has recommendations regarding adjuvant intravesical chemotherapy in relation to risk group stratification of NMIBC. ${ }^{1}$ Mitomycin $\mathrm{C}(\mathrm{MMC})$ is one of the commonly used agents for further adjuvant intravesical treatment of intermediate and highrisk NMIBT. Moreover, adjuvant thermochemotherapy with MMC has been presented as a hopeful treatment option for further intravesical therapy in patients with high-risk tumours. ${ }^{2}$ In this report, we present a case of a ureteral orifice and distal ureter stenosis developed after adjuvant intravesical therapy as a potential side effect of MMC thermotherapy.

\section{Case report}

A 65-year-old man underwent TURBT for a primary, highgrade, NMIBT (pT1G3) localized at the junction of the bladder base and left lateral bladder wall, about $2 \mathrm{~cm}$ away from the left ureteral orifice. The resection did not include the left ureteric orifice region and both the bladder wall and orifice were intact after resection. One early intravesical instillation of $40 \mathrm{mg}$ MMC in $50 \mathrm{~mL}$ saline was administered postoperatively. The convalescence period was uncomplicated. A secondary resection was performed 4 weeks after the primary resection and the pathological assessment revealed inflammatory reactive changes with infiltration of eosinophils and giant cells. Ultrasonographic evaluation of the urogenital tract was normal 2 months after the primary resection. In light of the pathological evaluation of the primary tumour, we planned to administer further adjuvant intravesical immunotherapy with Bacillus Calmette-Guérin (BCG). However, the patient was unable to supply the BCG preparations. Therefore, we decided to continue further adjuvant intravesical treatment with MMC thermochemotherapy.

After the decompression of the bladder, the thermotherapy was administered with the usage of the bladder wall thermochemotherapy (BWT) system (Pelvix TT system, Elmedical Ltd., Hod Hasharon, Israel) by insitillation of $40 \mathrm{mg} \mathrm{MMC}$ in $50 \mathrm{mg}$ distilled water for 50 minutes with uniform $44^{\circ} \mathrm{C}$ temparature on the bladder wall. This induction therapy was performed weekly for 6 weeks. The patient then complained about ambiguous flank pain on the left side after 6 doses of thermochemotherapy. The ultrasonografic evaluation of the kidneys revealed a mild-to-moderate dilatation of left ureter and collecting system. Non-contrast and contrast-enhanced abdominal computed tomography scan confirmed left hydroureteronephrosis without concomitant urinary stones (Fig. 1). Transurethral resection of the obstructed left ureteral orifice was performed. The pathological assessment showed inflammatory reactive urothelial changes, foreign body reaction and cystitis without tumoural involvement. In the follow-up period 8 months later, re-stenosis of the left ureteric orifice with left hydroureteronephrosis occurred. The scarring tissue required a new transurethral resection followed by the insertion of a ureteral stent. Pathology showed active chronic inflammation, including fibroblasts. The ureteral stent was removed 4 weeks after the orifice resection and there was no sign of tumour recurrence during the cystoscopy. Renal 


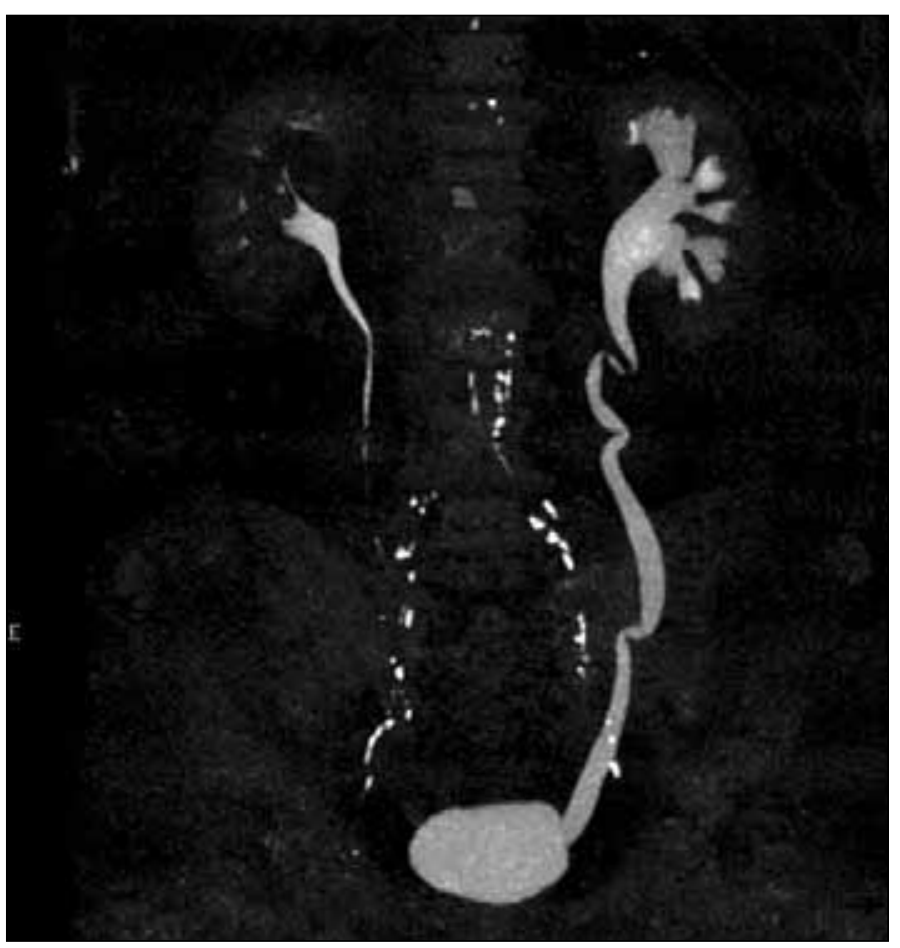

Fig. 1. Three-dimensional abdominal computed tomography image reveals a left hydroureteronephrosis.

ultrasound was normal 2 months after this final resection and the patient was asymptomatic.

\section{Discussion}

Local tissue inflammation, necrosis and related complications related to intravesical MMC administration have been reported. Perivesical inflammation and necrosis, ${ }^{3}$ necrosis of the glans penis ${ }^{4}$ and urethra, ${ }^{5}$ ureteral stricture development, ${ }^{6}$ allergic reactions and bladder wall calcifications ${ }^{7}$ are rarely declared side effects. These complications are often reported as an adverse effect of immediate postoperative MMC instillation. To our knowledge, this is the first case reporting on ureteral stricture formation after MMC thermochemotherapy for further intravesical chemotherapy of a high-grade NMIBT, without resection of the orifice during TURBT.

Transurethral resection of the ureter orifice may cause temporary or overt ureteral strictures. ${ }^{8}$ Oehlschläger and colleagues reported a case of ureteral stricture following TURBT and early adjuvant MMC instillation. ${ }^{6}$ Although they resected the left ureteral orifice, the authors claimed that the ureteral stricture formation was associated with MMC administration regarding the length of time until diagnosis of ureteral stenosis. In the present case, the ureter orifices, as well as the bladder wall, were intact after transurethral resection. The symptoms of hydroureteronephrosis occurred after 6 doses of MMC thermochemotherapy. In our case, although we did not resect the left ureteral orifice and a recurrent tumour did not occur around the orifice region, the formation of a distal ureteral stricture seems to be a consequence of MMC thermochemotherapy. Chemical cystitis related with intravesical MMC administration develops on the basis of bladder wall inflammation ${ }^{9}$ and complications associated with fibrosis seems to be as a result of this process. Also, in our case, thermotherapy enhanced the effects of chronic inflammation that induced ureteral stricture formation.

\section{Conclusion}

Thermotherapy with intravesical MMC may introduce side effects and affect outcomes. Therefore, rigorous follow-up with imaging is important.

Competing interests: Dr. Umul, Dr. Altok, Dr. Güneş, Dr. Şahin and Dr. Divrik all declare no competing financial or personal interests.

This paper has been peer-reviewed.

\section{References}

1. Babjuk M, Burger M, Zigeuner R, et al. EAU Guidelines on Non-Muscle-invasive Urothelial Carcinoma of the Bladder: Update 2013. Eur Urol 2013;64:639-53. http://dx.doi.org/10.1016/j.eururo.2013.06.003

2. Lammers RJ, Wities JA, Inman BA, et al. The role of a combined regimen with intravesical chemotherapy and hyperthermia in the management of non-muscle-invasive bladder cancer: A systematic review. Eur Urol 2011;60:81-93. http://dx.doi.org/10.1016/i.eururo.2011.04.023

3. Fazlioglu A, Tandogdu Z, Kurtulus $\mathrm{FO}$, et al. Perivesical inflammation and necrosis due to mitomycin $\mathrm{C}$ instillation after transurethral resection of bladder tumor: We must be vigilant! Urol Int 2009;83:362-3. http://dx.doi.org/10.1159/000241684

4. Neulander EZ, Lismer L, Kaneti J. Necrosis of the glans penis: A rare complication of intravesical therapy with mitomycin c. J Urol 2000;164:1306. http://dx.doi.org/10.1016/S0022-5347(05)67168-6

5. Brady JD, Assimos DG, Jordan GH. Urethral slough: A rare and previously unreported complication of intravesical mitomycin. J Urol 2000; 164:1305. http://dx.doi.org/10.1016/S0022-5347(05)67167-4

6. Oehlschläger $S$, Loessnitzer $A$, Froehner $M$, et al. Distal ureteral stenosis after early adjuvant intravesical mitomycin C application for superficial bladder cancer. Urol Int 2003;70:74-6. http://dx.doi. org/10.1159/000067698

7. Soloway MS, Perito PE. Superficial bladder cancer: diagnosis, surveillance and treatment. J Cell Biochem Suppl 1992;161:120-7. http://dx.doi.org/10.1002/icb.240501323

8. Mano R, Shoshany 0 , Baniel J, et al. Resection of ureteral orifice during transurethral resection of bladder tumor: Functional and oncologic implications. J Urol 2012; 188:2129-33. http://dx.doi.org/10.1016/i. juro.2012.08.006

9. Van Helsdingen PJ, Rikken CH, Sleeboom HP, et al. Mitomycin C resorption following repeated intravesical instillations using different instillation times. Urol Int 1988;43:42-6. http://dx.doi. org/10.1159/000281301

Correspondence: Dr. Mehmet Umul, Assistant professor of Urology, Suleyman Demirel University, Faculty of Medicine, Department of Urology, SDÜ Araştırma Uygulama Hastanesi Doğu Kampüsü, 32260 Çünür, Isparta, Turkey; mehmetumu|@sdu.edu.tr 